\title{
Low-Flow Polytetrafluoroethylene Accesses: Ultrasound Surveillance and Preemptive Interventions Ensure Long-Term Patency
}

\author{
Jan Malik $^{\mathrm{a}}$ Vladimir Tuka ${ }^{\mathrm{a}}$ Eva Chytilova $^{\mathrm{a}}$ Magdalena Mokrejsova $^{\mathrm{b}}$ \\ Martin Masek $^{c}$ Marcela Slavikova $^{d}$ \\ a Third Department of Internal Medicine, ${ }^{b}$ Department of Nephrology, ${ }^{\mathrm{c} D e p a r t m e n t}$ of Radiology, and \\ ${ }^{\mathrm{d} D e p a r t m e n t}$ of Cardiovascular Surgery, First Faculty of Medicine, Charles University and General University \\ Hospital, Prague, Czech Republic
}

\section{Key Words}

Hemodialysis $\cdot$ Stenosis $\cdot$ Vascular access $\cdot$ Ultrasonography

\begin{abstract}
Background: Vascular accesses (especially polytetrafluoroethylene grafts) with a permanently low flow (Qa $<600 \mathrm{ml} /$ $\mathrm{min}$ ) are prone to thrombosis and thus have short patency. The reason for a permanently low flow is usually medial calcinosis of the inflow artery in diabetics. We retrospectively studied the long-term patency of low-flow grafts with careful ultrasound surveillance and preemptive interventions. Methods: Twenty subjects with Qa permanently $<600 \mathrm{ml} /$ min were included. Ultrasound surveillance was performed every 3 months in addition to classical monitoring techniques. Significant stenosis was strictly defined as the combination of B-mode narrowing $>50 \%+>2$-fold peak systolic velocity increase +1 additional criterion (residual diameter $<2.0 \mathrm{~mm}$ or flow volume decrease by $>20 \%$ ). Such stenoses were treated by preemptive percutaneous intervention. Primary and secondary patencies were calculated. Results: The primary patency was $357 \pm 316$ days and the secondary (cu-
\end{abstract}

mulative) patency was $996 \pm 702$ days. The number of interventions was 2.09/patient year, but $>10$ in $6(33 \%)$ subjects. 93 and $80 \%$ of grafts were patent 1 and 2 years after access creation, respectively. Conclusion: Low-flow accesses undergoing ultrasound surveillance with strict diagnostic criteria and preemptive interventions had patencies similar to accesses with normal Qa in our study. This was enabled by a relatively high rate of interventions.

Copyright $\odot 2010$ S. Karger AG, Basel

\section{Introduction}

Vascular access is a 'lifeline' for end-stage renal disease patients. Especially in Europe, vascular accesses with polytetrafluoroethylene (PTFE) grafts are created in subjects with no suitable veins for regular dialysis cannulations. Therefore, patients with PTFE accesses are generally more ill and have limited possible sites for the next accesses. Moreover, the hemodialysis population has changed during last years - there are more elderly patients, diabetics, and patients with congestive heart fail-

\section{KARGER}

Fax +41613061234 E-Mail karger@karger.ch www.karger.com
(C) 2010 S. Karger AG, Basel

$1420-4096 / 10 / 0333-0181 \$ 26.00 / 0$

Accessible online at:

www.karger.com/kbr
Dr. Jan Malik

Third Department of Internal Medicine, General University Hospital

$\mathrm{U}$ nemocnice 2

CZ-12808 Prague 2 (Czech Republic)

Tel./Fax +420 224923 852, E-Mail malik.jan@vfn.cz 
ure. These factors are responsible for the more frequent access complications, namely medial calcinosis caused by diabetes mellitus and by kidney failure which per se leads to limited inflow. Medial calcinosis, severe atherosclerosis of the feeding arteries or severe congestive heart failure are responsible for chronically low access flow (Qa $<600 \mathrm{ml} / \mathrm{min}$ ). Patients with permanently low Qa are at the highest risk of access thrombosis. This situation must be differentiated from a sudden Qa decrease in a patient with an otherwise normal Qa. That is usually due to outflow stenosis, which is reversible mainly by percutaneous angioplasty. A number of monitoring and surveillance techniques have been tested to prolong PTFE graft patency, but they still fail to keep PTFE grafts patent for a period longer than 1.5 years [1]. The surveillance techniques include a complex of methods, such as dynamic and static venous pressure measurements $[2,3]$, duplex Doppler ultrasonography, and Qa measurement. The latter is emphasized as the most reliable method in the last European [4] and American [5] guidelines: Qa $<600 \mathrm{ml} /$ min and/or reduction of flow by $>20 \% /$ month or $>25 \% / 4$ months are indications for angiography and preemptive intervention. The precise timing of intervention, especially of percutaneous transluminal angioplasty (PTA), is crucial because stenosis after angioplasty develops faster than de novo stenosis, suggesting that the vascular injury produced by angioplasty accelerates the underlying process of neointimal hyperplasia [6]. Unnecessary PTAs also increase the patient's pain and medical expenses.

Duplex Doppler ultrasonography surveillance combines anatomical imaging and measuring of Qa. However, this method has been criticized for high inter-observer variability. Several randomized clinical trials [7-9] also failed to document a prolongation of secondary patency (i.e. functional patency until either final failure or the abandonment of the access).

In fact, our randomized trial [10] was the only one which documented prolonged secondary patency of grafts by regular ultrasonography surveillance. Similar results were published by Martin et al. [11] in a subset analysis of a prospective randomized study. Dossabhoy et al. [12] reported reduced hospitalization rates and costs by duplex ultrasound surveillance, but not by sole flow surveillance.

Since our aforementioned randomized study [10], we perform regular ultrasound surveillance on all our patients with PTFE grafts in our center. We hypothesized that this surveillance would help to keep even accesses with a permanently low flow $(<600 \mathrm{ml} / \mathrm{min})$ patent, i.e. the group at the highest risk of graft failure. Therefore, the aim of this retrospective study was to describe the outcomes of low-flow PTFE grafts with the help of ultrasound surveillance and preemptive interventions in a large university hospital-based vascular access center.

\section{Methods}

Patients with low-flow PTFE grafts (defined as mean Qa of all measurements of $<600 \mathrm{ml} / \mathrm{min}$ and $<10 \%$ of Qa measurements of $>600 \mathrm{ml} / \mathrm{min}$ but $<900 \mathrm{ml} / \mathrm{min}$ ) were searched for in our database of 450 patients (between the years 2001 and 2009). Patients were included in this study only when their access was patent for a period of at least 3 months after creation and was suitable for hemodialysis. All of them underwent regular access ultrasonography every 3 months following the creation of the access. This period was shortened if a borderline stenosis was detected (see below). Low Qa grafts are known to have a shorter lifespan than grafts with normal Qa, so we decided not to create a group of normal Qa for comparison. Similarly, there was no classical 'control' group of low Qa grafts without ultrasound screening in this study - we found this idea unethical because it was at our center where the benefit of surveillance was proved [10] (opposed to others [7-9]). Besides ultrasonography, all patients were examined clinically on a regular basis and dynamic venous pressure was recorded during all hemodialysis sessions according to the guidelines $[4,5]$.

Grafts were examined using duplex Doppler ultrasound (broad-band linear array 3-11 MHz probe of SONOS 5500 device (Philips, USA)) as described earlier [10]. In brief, B-mode images and color-coded images were obtained from the feeding artery, arterial anastomosis, the whole graft, the venous anastomosis and the outflow vein. Centerline systolic velocities were obtained from the feeding artery and from the venous anastomosis in all grafts. Qa was measured in the venous part of the graft at least $2 \mathrm{~cm}$ distal to the venous anastomosis as a mean of 3 calculations. The peak systolic velocity ratio (PSR) was defined as the ratio of the peak velocities inside the stenosis and in an adjacent unaffected pre-stenotic segment. Stenoses were considered significant if there was a combination of $>50 \%$ lumen reduction in B mode and PSR $>2$, together with at least one of the following additional criteria: (1) residual diameter of $<2.0 \mathrm{~mm}$, and/or (2) blood flow reduction of $>25 \%$. Stenosis was considered borderline in the absence of any of the additional criteria. Patients with significant stenosis were referred to PTA, while those with borderline stenosis were advised to come for reexamination after 6-8 weeks. Within this period, the watch-and-wait strategy was maintained, i.e. direct referral to PTA in any suspicion of stenosis progression or other doubts in the hemodialysis unit (i.e. rise in venous pressure, changes in regular physical examination of the access, etc.).

Percutaneous balloon angioplasty or other interventions were indicated by: (1) dialysis staff; (2) vascular surgeon, and (3) access ultrasonography findings. Dialysis units indicated access angiography directly when access dysfunction was suspected. The following conditions were considered grounds for suspicion of access dysfunction: (1) abnormal physical findings (conversion of thrill to pulse, intensification of bruit at certain sites, edema of the extremity bearing the vascular access); (2) prolonged bleeding after needle withdrawal; (3) elevation of dynamic venous pressure; (4) decrease in Qa by $>25 \%$; (5) abnormal recirculation measure- 
ments, and (6) unexplained decreases in measurement of dialysis dose. All other angiographies and therapeutic interventions were performed as a result of hemodynamically significant stenosis occurrence on ultrasonography (see above for definition).

Primary patency (from graft placement until any type of intervention) and secondary patency (cumulative, until the final abandoning of the access) of the included grafts were recorded together with the number and types of interventions. Raw data of the included subjects and a Kaplan-Meier graph are used to present the results. Values are presented as mean \pm SD.

\section{Results}

We found 20 subjects aged $62.5 \pm 15.6$ years ( 6 males) in our database. Fourteen subjects (70\%) were diabetics, $90 \%$ of patients suffered from hypertension, $30 \%$ had coronary artery disease, $30 \%$ were current or ex-smokers, and 1 patient had congestive heart failure. Insufficient feeding artery dilatation after access creation caused by medial calcinosis untreatable by angioplasty (due to a length of $>10 \mathrm{~cm}$ ) was responsible for all included cases with low Qa. Nineteen subjects were on single anti-aggregation therapy (aspirin) throughout the study and 1 patient (case 8) was on warfarin. Eighty percent of the PTAs were indicated by duplex Doppler ultrasonography screening, i.e. there was no clear clinical suspicion of access stenosis.

Primary patency was $357 \pm 316$ days and secondary patency was $996 \pm 702$ days (range 89-2,550 days; fig. 1 ). The difference between primary and secondary patency was $640 \pm 540$ days. Detailed results are presented in table 1.

The high secondary patency ( $80 \%$ at 2 years) was enabled by the relatively high number of preemptive access interventions: 2.09 PTAs/patient year.

\section{Discussion}

This retrospective study shows that the secondary patency of low-flow grafts could be long enough when such grafts undergo regular ultrasound surveillance with preemptive interventions. The results in this small series of low-flow accesses are comparable to grafts with normal flow $[1,13]$.

Patients with permanently low Qa de facto fulfill one of the indications for angiography and preemptive intervention according to the guidelines ( $\mathrm{Qa}<600 \mathrm{ml} / \mathrm{min}$ ) [4, 5]. We have not found any study specifically investigating the efficacy of Qa monitoring in low-flow accesses. How-

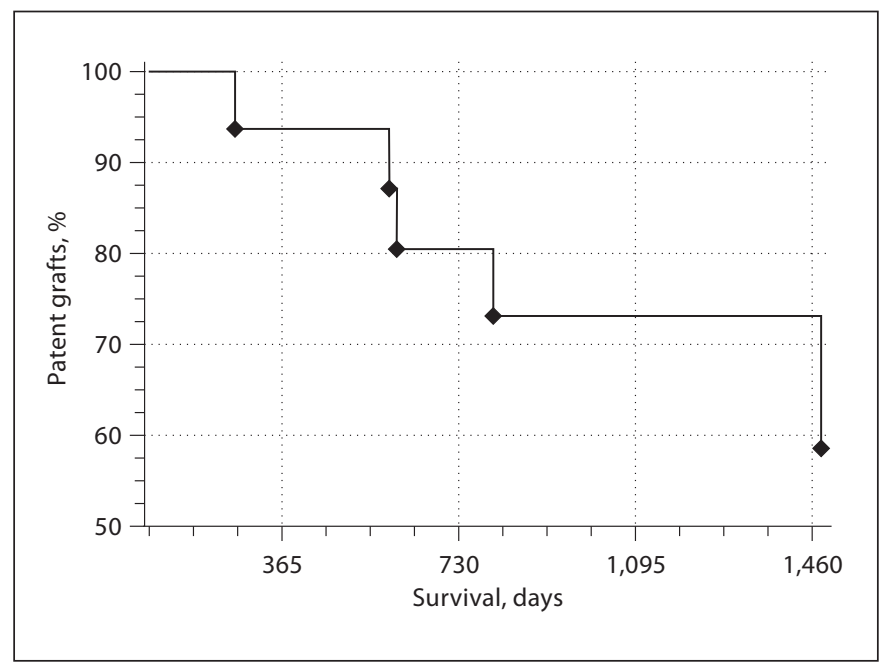

Fig. 1. Kaplan-Meier graph of the secondary (cumulative) patency of grafts.

ever, we can assume that because only the flow decline could be used as the indication for intervention, it would be even less specific than in the general access population. Patients are known to have wide hemodynamic variation during hemodialysis; therefore, the reproducibility of flow measurements from session to session is poor [14]. Flow and change in flow have been identified as inaccurate predictors of thrombosis in an interesting recent study when Qa was assessed every month [15]. Two randomized trials published to date failed to improve graft survival with the use of flow surveillance $[16,17]$. The reason for low Qa in this study was primarily diffuse medial calcinosis of the feeding artery. However, an unusually high number of graft stenoses caused by dialysis cannulations and their healing (table 1) probably also played a role. PTFE grafts with permanently low Qa $(<600 \mathrm{ml} / \mathrm{min})$ are uncommon - they represent $3 \%$ of our database. Qa is known to be negatively correlated with the risk of access thrombosis [14], but we still do not have criteria for individual risk of access thrombosis with sufficient sensitivity and specificity. In our opinion, this study shows that ultrasound screening is able to keep the accesses patent for a long time even in this high-risk group. It is another argument for the currently debated ultrasound surveillance [17-19]. Conversely, in the future we may be able to identify the low-risk group and choose not to perform surveillance in these patients. In other words, there is a need for risk stratification similar to that used in cardiovascular disease prevention. An alternative 
Table 1. Characteristics of included subjects and accesses

\begin{tabular}{|c|c|c|c|c|c|c|c|c|c|c|c|c|}
\hline $\begin{array}{l}\text { Patient } \\
\text { number }\end{array}$ & $\begin{array}{l}\text { Age } \\
\text { years }\end{array}$ & $\begin{array}{l}\text { Access } \\
\text { type }\end{array}$ & $\begin{array}{l}\text { Number of } \\
\text { previous } \\
\text { accesses }\end{array}$ & $\begin{array}{l}\text { Dia- } \\
\text { betes }\end{array}$ & $\begin{array}{l}\text { Primary } \\
\text { patency }\end{array}$ & $\begin{array}{l}\text { First } \\
\text { proce- } \\
\text { dure }\end{array}$ & $\begin{array}{l}\text { Number } \\
\text { of PTA } \\
\text { sessions }\end{array}$ & Site of stenosis & $\begin{array}{l}\text { Num- } \\
\text { ber } \\
\text { of TL }\end{array}$ & $\begin{array}{l}\text { Num- } \\
\text { ber of } \\
\text { reoper. }\end{array}$ & $\begin{array}{l}\text { Secondary } \\
\text { patency } \\
\text { days }\end{array}$ & $\begin{array}{l}\text { Patent } \\
\text { at last } \\
\text { control? }\end{array}$ \\
\hline 1 & 84 & FS & 0 & Yes & 169 & - & 0 & - & 0 & 0 & 169 & Yes \\
\hline $2^{1}$ & 83 & FS & 0 & No & 110 & - & 0 & - & 0 & 0 & 110 & Yes \\
\hline 3 & 79 & FL & 0 & Yes & 5 & $\mathrm{TL}$ & 12 & $12 \mathrm{OV}$ & 2 & 2 & 1,466 & Yes \\
\hline 4 & 78 & FS & 0 & Yes & 233 & $\mathrm{TL}$ & 15 & $14 \mathrm{G}, 2 \mathrm{AA}, 2 \mathrm{VA}$ & 1 & 1 & 1,339 & Yes \\
\hline 5 & 76 & FS & 0 & Yes & 179 & PTA & 5 & $5 \mathrm{VA}$ & 1 & 0 & 1,731 & Yes \\
\hline 6 & 74 & $\mathrm{FL}$ & 3 & Yes & 662 & PTA & 3 & $3 \mathrm{G}$ & 0 & 0 & 1,075 & Yes \\
\hline $7^{1}$ & 69 & FS & 0 & Yes & 89 & - & 0 & - & 0 & 0 & 89 & Yes \\
\hline $8^{1}$ & 65 & FL & 6 & No & 311 & $\mathrm{TL}$ & 5 & $4 \mathrm{VA}, 1 \mathrm{OV}$ & 1 & 0 & 719 & Yes \\
\hline 9 & 64 & FS & 1 & No & 143 & PTA & 11 & $11 \mathrm{G}, 3 \mathrm{VA}$ & 1 & 0 & 1,353 & Yes \\
\hline $10^{1}$ & 61 & FS & 0 & Yes & 221 & PTA & 1 & $1 \mathrm{VA}$ & 0 & 0 & 408 & Yes \\
\hline $11^{1}$ & 61 & FS & 0 & Yes & 96 & $\mathrm{TL}$ & 2 & $1 \mathrm{G}$ & 1 & 0 & 180 & Yes \\
\hline 12 & 61 & FS & 3 & Yes & 157 & PTA & 4 & $4 \mathrm{OV}$ & 0 & 0 & 602 & No \\
\hline 13 & 43 & $\mathrm{BA}$ & 6 & No & 1,102 & $\mathrm{TL}$ & 10 & $6 \mathrm{OV}, 4 \mathrm{VA}, 2 \mathrm{AA}$ & 2 & 0 & 2,550 & No \\
\hline 14 & 55 & FL & 3 & Yes & 974 & PTA & 4 & $4 \mathrm{OV}, 3 \mathrm{VA}, 1 \mathrm{G}$ & 0 & 0 & 1,821 & Yes \\
\hline 15 & 54 & FS & 1 & No & 381 & PTA & 14 & $10 \mathrm{VA}, 4 \mathrm{OV}$ & 0 & 1 & 1,479 & No \\
\hline 16 & 53 & FS & 0 & Yes & 458 & PTA & 14 & $8 \mathrm{G}, 7 \mathrm{VA}, 2 \mathrm{FA}, 1 \mathrm{VA}$ & 1 & 0 & 1,437 & Yes \\
\hline 17 & 41 & FS & 2 & Yes & 301 & PTA & 1 & $1 \mathrm{VA}$ & 2 & 0 & 587 & No \\
\hline 18 & 23 & FS & 0 & No & 934 & PTA & 7 & $6 \mathrm{G}, 3 \mathrm{VA}$ & 0 & 0 & 1,744 & Yes \\
\hline 19 & 62 & FS & 0 & Yes & 347 & PTA & 6 & $5 \mathrm{G}, 1 \mathrm{VA}, 1 \mathrm{OV}$ & 0 & 0 & 799 & No \\
\hline 20 & 63 & FS & 1 & Yes & 261 & $\mathrm{TL}$ & 0 & - & 1 & 0 & 269 & No \\
\hline
\end{tabular}

Access type: $\mathrm{FS}=$ forearm straight; $\mathrm{FL}=$ forearm loop; $\mathrm{BA}=$ brachial-axillary. Therapy: $\mathrm{TL}=$ thrombolysis; $\mathrm{PTA}=$ percutaneous transluminal angioplasty. Sites of access stenoses: FA = feeding artery; $\mathrm{AA}=$ arterial anastomosis; $\mathrm{G}=$ PTFE graft; $\mathrm{VA}=$ venous anastomosis; $\mathrm{OV}=$ outflow vein.

The type of the first procedure is presented - it determines the primary access patency. Notice that thrombolysis was the first procedure in $30 \%$ of patients, which documents the high risk of thrombosis in this group of patients. Sites of access stenoses treated by PTA are shown. During some sessions more than 1 site was treated. Notice that there are more than usual graft PTAs and the vast majority of PTAs treated re-stenoses.

${ }^{1}$ Patients who died during follow-up, all with patent access. explanation of the long access patency in this study is that low Qa does not possess an increased risk of graft thrombosis. We have found this idea not likely due to the impact of Qa documented in other studies [14] and also mentioned in the guidelines $[4,5]$.

Duplex Doppler ultrasonography revealed many significant but clinically 'silent' stenoses in this study, including 9 of 17 representing primary patency. Therefore, this study further supports ultrasound graft surveillance which is advocated by some $[10,12]$ but not all $[7-9,18]$. There could be several reasons explaining the different outcomes of ultrasound surveillance in our and other studies $[19,20]$. They include differences in sample size, access age at inclusion, organization of access care, and also various criteria of stenosis significance definition. Some centers $[8,21]$ use the $>50 \%$ diameter narrowing in $\mathrm{B}$ mode as the only criterion of significant stenosis. We think that this approach is not precise enough because various technical and anatomical irregularities might influence the result. Others [9], including us [10], combine the findings in B mode with a peak systolic velocity increase, which is similar to the examination of peripheral arteries. Our definition of significant stenoses also includes additional criteria (see Methods) which differentiate significant and borderline stenoses. The delaying of PTA is safe in borderline stenoses of PTFE grafts with normal flow [22] and we also used this approach in this study. In other words, precise definition of significant stenosis would not only help us to avoid unnecessary interventions, but also to prevent access thrombosis. A highly experienced ultrasound operator is a must. In our center, access ultrasonography is performed directly by doctors and all of them have the experience of at least 1,000 vascular examinations. 
The grafts in this study were kept patent at the price of 2.09 PTAs/patient year, but by more than 10 PTAs in 6 (33\%) patients. The higher cost of this approach was, according to us, balanced by the long secondary patency in these seriously ill patients. Percutaneous interventions included only PTAs in this study - no stent was inserted. Implantation of stents could theoretically lower the number of procedures. However, the available data on stent usage in vascular accesses is still controversial [23], despite some newer studies reporting longer graft patency after stenting [24].
The main limitations of this study are the relatively low sample size and the lack of a control group. However, grafts with Qa permanently $<600 \mathrm{ml} / \mathrm{min}$ are infrequent. This is also the reason why this study was retrospective. We decided not to form a control group with normal Qa because it is well known that low Qa is associated with a higher risk of graft thrombosis.

\section{Acknowledgement}

This study was supported by grant NS10590/3 of the Internal Grant Agency, Czech Ministry of Health.

\section{References}

1 Huber TS, Carter JW, Carter RL, Seeger JM: Patency of autogenous and polytetrafluoroethylene upper extremity arteriovenous hemodialysis accesses: a systematic review. J Vasc Surg 2003;38:1005-1011.

-2 Schwab SJ, Raymond JR, Saeed M, Newman GE, Dennis PA, Bollinger RR: Prevention of hemodialysis fistula thrombosis. Early detection of venous stenoses. Kidney Int 1989; 36:707-711.

- 3 Sullivan KL, Besarab A, Dorrell S, Moritz MJ: The relationship between dialysis graft pressure and stenosis. Invest Radiol 1992;27: 352-355.

4 Tordoir J, Canaud B, Haage P, et al: EBPG on vascular access. Nephrol Dial Transplant 2007;22(suppl 2):ii88-ii117.

5 Sidawy AN, Spergel LM, Besarab A, et al: The Society for Vascular Surgery: clinical practice guidelines for the surgical placement and maintenance of arteriovenous hemodialysis access. J Vasc Surg 2008;48(suppl):2S$25 \mathrm{~S}$

6 Chang CJ, Ko PJ, Hsu LA, et al: Highly increased cell proliferation activity in restenotic hemodialysis vascular access after percutaneous transluminal angioplasty: implication in prevention of stenosis. Am J Kidney Dis 2004; 43:74-84.

7 Lumsden AB, MacDonald MJ, Kikeri D, et al: Prophylactic balloon angioplasty fails to prolong the patency of expanded polytetrafluoroethylene arteriovenous grafts: results of a prospective randomized study. J Vasc Surg 1997;26:382-392.

$\checkmark 8$ Ram SJ, Work J, Caldito GC, et al: A randomized controlled trial of blood flow and stenosis surveillance of hemodialysis grafts. Kidney Int 2003;64:272-280.
9 Robbin ML, Oser RF, Lee JY, et al: Randomized comparison of ultrasound surveillance and clinical monitoring on arteriovenous graft outcomes. Kidney Int 2006;69:730735.

10 Malik J, Slavikova M, Svobodova J, et al: Regular ultrasonographic screening significantly prolongs patency of PTFE grafts. Kidney Int 2005;67:1554-1558.

11 Martin LG, MacDonald MJ, Kikeri D, Cotsonis GA, Harker LA, Lumsden AB: Prophylactic angioplasty reduces thrombosis in virgin $\mathrm{PPTFE}$ arteriovenous dialysis grafts with greater than $50 \%$ stenosis: subset analysis of a prospectively randomized study. J Vasc Interv Radiol 1999;10:389-396.

-12 Dossabhoy NR, Ram SJ, Nassar R, Work J Eason JM, Paulson WD: Stenosis surveillance of hemodialysis grafts by duplex ultrasound reduces hospitalizations and cost of care. Semin Dial 2005; 18:550-557.

13 Schild AF, Perez E, Gillaspie E, Seaver C, Livingstone J, Thibonnier A: Arteriovenous fistulae vs. arteriovenous grafts: a retrospective review of 1,700 consecutive vascular access cases. J Vasc Access 2008;9:231-235.

- 14 Ram SJ, Nassar R, Sharaf R, Magnasco A, Jones SA, Paulson WD: Thresholds for significant decrease in hemodialysis access blood flow. Semin Dial 2005; 18:558-564.

15 Ram SJ, Nassar R, Work J, Abreo K, Dossabhoy NR, Paulson WD: Risk of hemodialysis graft thrombosis: analysis of monthly flow surveillance. Am J Kidney Dis 2008;52:930938 .

16 Moist LM, Churchill DN, House AA, et al: Regular monitoring of access flow compared with monitoring of venous pressure fails to improve graft survival. J Am Soc Nephrol 2003; 14:2645-2653.
17 Ram SJ, Work J, Caldito GC Eason JM, Pervez A, Paulson WD: A randomized controlled trial of blood flow and stenosis surveillance of hemodialysis grafts. Kidney Int 2003;64:272-280.

18 Tonelli M, James M, Wiebe N, Jindal K, Hemmelgarn B: Ultrasound monitoring to detect access stenosis in hemodialysis patients: a systemic review. Am J Kidney Dis 2008;51:630-640.

19 Tuka V, Malik J: Vascular access surveillance - no benefit? Am J Kidney Dis 2008;52: 628.

20 Malik J: Ultrasound and graft patency. Kidney Int 2006;70:1375-1376.

-21 Lumsden AB, MacDonald MJ, Kikeri D, et al: Prophylactic balloon angioplasty fails to prolong the patency of expanded polytetrafluoroethylene arteriovenous grafts: results of a prospective randomized study. J Vasc Surg 1997;26:382-392.

22 Tuka V, Slavikova M, Krupickova Z, Mokrejsova M, Chytilova E, Malik J: Short-term outcomes of borderline stenoses in vascular accesses with PTFE grafts. Nephrol Dial Transplant 2009;24:3193-3197.

23 Yevzlin A, Asif A: Stent placement in hemodialysis access: historical lessons, the state of the art and future directions. Clin J Am Soc Nephrol 2009;4:996-1008.

24 Chan MR, Bedi S, Sanchez RJ, Young HN, Becker YT, Kellerman PS, Yevzlin AS: Stent placement versus angioplasty improves patency of arteriovenous grafts and blood flow of arteriovenous fistulae. Clin J Am Soc Nephrol 2008;3:699-705. 